\title{
Editorial
}

\section{El bienio perdido}

"- Podrias decirme, por favor, qué camino he de tomar para salir de aqui? - Depende mucho del punto adonde quieras ir - contestó el gato [de Cheshire].

- Me da casi igual dónde-dijo Alicia - Entonces no importa qué camino sigas dijo el gato

- ...siempre que llegue a alguna parte añadió Alicia, a modo de explicación. - iAh!, seguro que lo consigues - dijo el gato - si caminas lo suficiente."

ALICIA EN EL PAÍS DE LAS MARAVILLAS.

Lewis Carrol.

omo están las cosas y después de dos largos años es posible imaginar al segundo gobierno de Arena en la misma situación y haciendo las mismas preguntas que Alicia. El gato de Cheshire tendría razón, si camináramos lo suficiente llegaríamos a alguna parte. Aunque por ahora no nos sabemos en parte alguna. Y, por otro lado, sería mejor que antes de comenzar supiéramos, aunque sea levemente, hacia donde podríamos dirigirnos sin llegar a pensar que nos "da casi igual donde".

No es por desorientación que debemos definir el rumbo aunque el gobierno 
muestre no tener otras opciones. Las elecciones estratégicas expresadas han sido erráticas y de corta duración y sustentabilidad. Una veces ha planteado la continuidad del gobierno anterior ( $¿$ hacia el desarrollo de los servicios y el comercio?); otras nos ha ofrecido (¿o amenazado?) convertirnos en una enorme zona franca; otras en un dinámico paraíso turístico y, hasta hace muy poco - siguiendo los consejos de los poderosos intereses agrarios, que se reicorporan con fuerza al estado y los últimos que más recientemente le han hablado al oído-- nos ha propuesto sin mucho entusiasmo volver a la tierra. De cualquier manera, a dos años de su llegada, aún no decide caminar lo suficiente para algún lado y todo indica que el tiempo y la casualidad decidirán la orientación posible.

En este no ir a parte alguna se han cerrado los dos primeros años del gobierno de Calderón Sol que han sido un desandar el camino de la primera gestión arenera. El consenso fundamental de los Acuerdos de Paz, base privilegiada para la estabilidad y la dinámica económica está fragmentándose y tiende a desaparecer; el mismo gobierno se ha dedicado a debilitarlo. A la actual administración se le están esfumando los logros anteriores y se le han acumulado problemas socio-políticos de primer orden para los cuales no anticipa solución alguna.

Las indecisiones, los compromisos políticos con funcionarios corruptos, las insuficiencias y falta de capacidad institucional y profesional, la pervivencia de pautas y estructuras autoritarias, la falta de visión en una situación de cambio global y nacional, el temprano proceso para definir pre-candidatos presidenciales en el partido de gobierno, todo ésto y otras causales, han llevado a una encrucijada al actual gobierno atribulado, por otra parte, por no encontrar ideas y medidas económicas y socio-políticas eficientes que saquen de males a la desmejorada situación nacional. ¿Hasta qué punto las tensiones sociales, que se incrementan a igual velocidad que el uso violento de la fuerza policial, comenzarán a revertir los limitados avances democráticos alcanzados hasta el momento?

Dos años después de una categórica victoria electoral, el resultado de un gobierno que se esperaba hiciera lo contrario es indiscutible: falta de rumbo estratégico, desaceleración económica, paros comerciales en importantes ciudades de provincia, críticas empresariales, demandas y protestas populares y cupulares, fortalecimiento de la propensión al autoritarismo, signos incuestionables de un peligroso retorno al terrorismo. La sociedad muestra una fragmentación indetenible que ha sobrepasado las acciones y medidas gubernamentales que han resultado ineficientes para las tareas que necesitamos para la recuperación social, económica y política.

No es extraño, entonces, que el primer bienio termine entre el malestar ciudadano, la intranquilidad de las masas, la casi rebelión de las élites y la cautela internacional, en especial de la inversión, para acercarse al país. ¿Qué significan las características señaladas en el párrafo anterior para el orden social y los procesos de democratización y de formación ciudadana? Nos interesa re- 
saltar, más allá de las dramáticas estadísticas, los impactos que sufre la sociedad con los movimientos de los elefantes, para utilizar una famosa frase que llama así a los funcionarios gubernamentales más importantes.

Desde nuestra perspectiva, la desaceleración económica es mucho más que decrementos en tasas de distinto orden económico, es la antesala y reflejo de problemas económicos más desastrosos. Muestra la incapacidad del gobierno para crear, ampliar, consolidar y sostener el mercado, alfa y omega de la ideología que aceptan sus más conspicuos funcionarios. Las medidas macroeconómicas para protegerlo (restricción y encarecimiento del dinero, principalmente) producen menos empleos y menos mercado. Aquí hay una "señal" de que la sociedad de mercado es más que un dogma, un deseo o una voluntad ciega e irreflexiva de improvisados neoliberales. Más que una realidad virtual es un proceso, una construcción- a esta altura de la globalización -más consciente que la simple concurrencia de las fuerzas ciegas del "libre" mercado y la competencia de fronteras abiertas, si es que alguna vez ha sido real esta abstracción.

La "vía rápida" a la globalización fracasa por la misma racionalidad del paradigma neoliberal asumido, a saber, la necesidad del mercado. Las débiles estructuras mercantiles del país muestran los estrechos límites de las reformas "orientadas al mercado" que han dejado al descubierto la necesidad de tiempos y planes previos para enbarcarse en una aventura económica tan fuerte y peligrosa. La "vía lenta" de integración de las corporaciones empresariales con riesgos razonables y manejables es un reto racional aún no descartado socialmente frente a los resultados de la opción gubernamental del "fast track".

El subsidio, el crédito blando, el sacrificio fiscal, los incentivos prolongados han sido parte central para todos los procesos productivos del país (agricultura, industria, comercio, servicios, etc.) y no sólo de los servicios sociales públicos. Este comportamiento no podrá hacerse desaparecer con un gesto de magia o de impaciencia.

Hasta el momento, las fuerzas políticas que dirigen el gobierno y al partido ARENA no han comprendido que se requiere de un "pacto social"- $y$, por supuesto, también político — que proporcione el marco para la transición hacia esa sociedad de mercado con democracia, haciendo peligrar la misma transición al establecer procesos de decisión excluyentes e impositivos. Diversos grupos preocupados por esta nueva ola de exclusiones llaman a la "construcción" o "a la constitución del proyecto o agenda" de nación frente a la indiferencia del gobierno, al cual no le ha importado intercambiar los costos de oportunidad de "pactos de nación" por pírricos e insulsos prestigios personales o partidarios, como terminó siendo el pacto de San Andrés, según versión del mismo presidente de la república.

Los paros en la zona oriental del país (Usulután y San Miguel) son heçhos de 
resistencia y presión civil y una manifestación de la lucha sorda entre los impulsores del estado neoliberal, globalizado, y los que requieren del estado autoritario fuerte, subvencionador y garante de los productores nacionales. En oriente, los comerciantes y otras fuerzas socio-políticas (muchas de ellas nacionales y del mismo partido oficial), entre ellas connotadas fracciones agrarias, pidieron "mano dura" (¿manu militari?) en contra de la delincuencia.

El gobierno a cambio les proporcionó una ley dura de emergencia a nivel nacional -que echa para atrás algunos avances judiciales y en derechos humanos de los Acuerdos de Paz - y les condonó parte de la deuda agraria, que para los grupos agrarios aún no es suficiente como subvención estatal. El impacto del paro de Usulután ha dejado huella a nivel constitucional, judicial y financiero como ningún otro grupo social o fuerza política había logrado hacerlo antes por medio de presiones y movilizaciones similares. En San Miguel, por otra parte, es claro el rechazo al equilibrio fiscal y a las medidas de estabilización macroeconómica del estado neoliberal central, ¿la política que seguirá el gobierno será de enfrentamiento, anulación o cooptación por considerarlos grupos nada modernos y en proceso de extinción?

El gobierno, en otro ámbito y hasta el momento, no ha logrado articular políticas sociales eficientes que frenen el acelerado avance de la desintegración social, indicado por la imbatible delincuencia común y organizada, las maras y la violencia estudiantil, la violencia intrafamiliar y, en especial, en contra de los niños, la indetenible (¿y estimulada?) emigración de buena parte de nuestra población activa.

No ha logrado estimular el restablecimiento y funcionamiento de la familia, ni las instituciones sociales comunales, ni las redes sociales que cohesionan e integran a la sociedad. Ha preferido combatir los problemas sociales por medio de la fuerza policial y judicial, provocando cárceles llenas, inoperancia judicial y creciente acción delincuencial. Las instituciones sociales estatales, tales como el FIS o la SRN - ahora fusionados - se han convertido en verdaderos instrumentos electorales partidarios. En medio de este panorama, los esfuerzos modernizantes y descentralizadores de la reforma educativa brilla solitaria en un horizonte donde la modernización equivale a privatización exclusivamente.

El gobierno no valora los esfuerzos de otros componentes de nuestra sociedad que actúan, pese a las dificultades y limites de sus recursos, en el restablecimiento de estas redes sociales, en el cemento de la nueva realidad social. Las iglesias, las ONGs y las nuevas asociaciones de la sociedad civil tratan de sustituir o restituir a las instituciones sociales anteriores que han sido deterioradas por la guerra y por la crisis económica y política. Hay verdaderos logros en este espacio ahora amenazado por el mismo gobierno y otra ley "dura" en su contra. A la menor provocación, el gobierno, y también las autoridades legislativas incluida la oposición, hay que reconocerlo- responden con proyectos de ley a 
diestra y siniestra, y mientras más "duros" mejor. El pasado autoritario pesa más de lo que aceptamos en nuestra cultura política.

Existe, también, la desintegración política expresada en diversos ámbitos de la actividad política. Por ejemplo, en los hechos impunes de corrupción en las municipalidades e instituciones de gobierno; en la permanente fragmentación y lucha facciosa entre los partidos políticos. Pero el indicador más importante es la desafección política ciudadana con relación a los partidos políticos, el sistema político y las instituciones del gobierno. El proceso de ciudadanización, si real, se caracteriza por la incertidumbre, el desánimo y la desconfianza en su entorno político. Aquí la tolerancia gubernamental no ha tenido límites ante la destrucción de los canales participativos. El mismo Tribunal Supremo Electoral ha entrado en crisis al no poder ampliar, desde hace ya casi cuatro años, la base ciudadana para la participación electoral. La imagen más cercana a la actual situación socio-política es la de estar suspendidos en el aire con la sensación de que al romperse este equilibrio estaríamos más cerca de la catástrofe y del caos que de la estabilidad política y del crecimiento y el desarrollo socioeconómicos.

El gobierno no repara en la profundidad de la encrucijada en que se encuentra. Por un lado, está la protesta y la movilización popular protagonizada por diversos grupos de base como los desmovilizados de guerra, los afectados por los incumplimientos e insuficiencias de los acuerdos de paz, los trabajadores industriales y de maquilas, empleados públicos despedidos y amenazados por la privatización y la modernización, etc. Por otro lado, el gobierno se enfrenta a la inconformidad y el recelo de las cúpulas empresariales. ANEP y ASI mantienen posiciones razonadas y firmes frente al incremento de los impuestos (IVA e impuesto sobre la renta), la reducción arancelaria y la nunca abordable reconversión industrial; empresarios descontentos por la corrupción e ilegalidad de las licitaciones públicas que obedecen al mercado de influencias políticas mas que a la normatividad legal; los pequeños y medianos empresarios del transporte frente a la corrupción y la disminución de subsidios. $\mathrm{Y}$ los pequeños y medianos empresarios de la rama textilera amenazados por las maquilas internacionales con base en el país y la región centroamericana.

La mayoría de grupos se sienten aislados, desintegrados, sin certidumbre de pertenencia a desarrollo alguno. Cada grupo ha tenido que reaccionar frente a las medidas aisladas y a la desidia del gobiemo. A su manera, la sociedad civil, popular o cupular, ha producido acciones de protesta legítima, cada sector - frente a los vacíos programáticos - ha tenido que elaborar propuestas estratégicas para el desarrollo desde su propia perspectiva y todas las asociaciones corporativas han generado una creciente desconfianza hacia un gobierno que no ha mostrado sensibilidad, habilidad y prudencia para integrar a sus decisiones estas sugerencias específicas. Esto muestra que la ciudadanía social es todavía un objetivo por alcanzar, para grupos populares y cupulares, lo mismo que la real definición de la 
ciudadanía política.

A dos años de iniciado el actual gobierno, la sociedad salvadoreña está cada vez más dividida y aislada. Le falta un elemento fundamental de la unidad social y política: la confianza en las acciones gubernamentales para solucionar demandas ciudadanas. Los diversos fragmentos sociales están cada cada vez más alejados de la dinámica estatal que se desvaloriza como elemento puente entre diversos intereses sociales y políticos.

Desde otro ángulo, no es posible construir la democracia manteniendo pobre a más de la mitad de la población y, mucho menos, con políticas excluyentes que, en forma premeditada, producen pobreza y deterioro social en grandes sectores de la sociedad. No es posible crear un orden político libre e igualitario si se mantienen políticas que de manera visible favorecen a sectores siempre privilegiados y cada vez más concentrados. No es posible gobernar de manera democrática sin considerar las demandas de los sectores más importantes de la sociedad y sin integrarlos de acuerdo al desarrollo que cada uno de ellos presenta, sin protegerlos del rezago y la vulnerabilidad.

Comprendemos que la indecisión estratégica del gobierno no proviene sólo del carácter y limitaciones personales manifiestas de los miembros del gabinete y del mismo jefe de Estado - quien por cierto tiende cada vez más a utilizar el "insulto ejecutivo" que el diálogo y la discusión abierta para buscar el buen gobierno. Sería un grave simplismo verlo de esa manera. El marco social y político de este impasse de decisión es producto de correlaciones económicas y políticas nacionales e internacionales y de tendencias socio-políticas más profundas. No obstante, la conducción personal también tiene su especial e importante contribución en las formas, metodologías y procedimientos del proceso de decisiones que caracterizan como exclusionista o participativo a un régimen político.

De nuevo, la carencia de sentido estratégico, la desaceleración económica, las demandas y protestas no sólo de las masas sino de las élites, la desintegración social y política, el terrorismo contra personalidades políticas, la proclividad al autoritarismo hacen pensar que no hemos avanzado en la constitución de la nueva sociedad y que la antigua, ante el vacío que no es ocupado por nuevas prácticas y acciones, se podría prolongar sin necesidad hasta el peligro de la restauración del antiguo régimen. No podemos seguir perdiendo el tiempo ni creer posible la compatibilidad de la democracia con la exclusión socio-económica, ni apostar más al debilitamiento político de los opositores o al enfrentamiento jurado con quienes tienen distintos intereses, a riesgo, claro está, de repetir las preguntas al gato de Cheshire no en el país de las maravillas sino desde el fondo del cuarto mundo. 